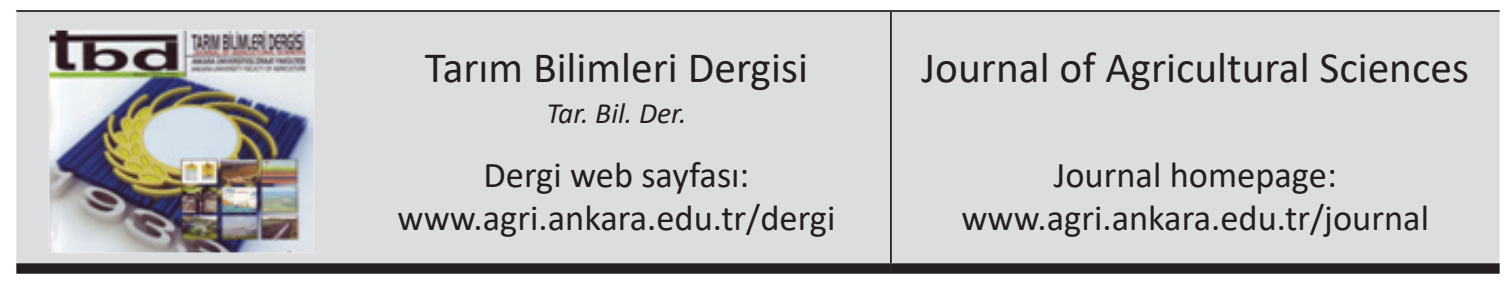

\title{
A Prototype Downdraft Gasifier Design with Mechanical Stirrer for Rice Straw Gasification and Comparative Performance Evaluation for Two Different Airflow Paths
}

\author{
İbrahim Savaş DALMIŞş, Birol KAYISŞOĞLU ${ }^{b}$, Serkan TUĞ ${ }^{c}$, Türkan AKTAŞ ${ }^{b}$, Mehmet Recai DURGUT ${ }^{\mathrm{b}}$, \\ Figen TAŞÇI DURGUT ${ }^{b}$

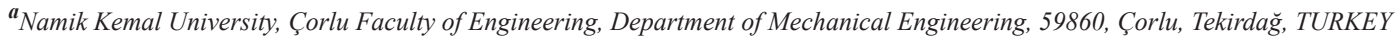

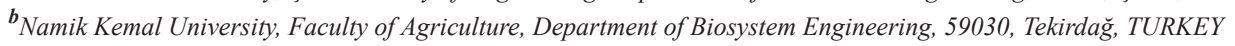 \\ ${ }^{c}$ Namik Kemal University, Vocational School Technical Sciences, 59030, Tekirdağ, TURKEY
}

\section{ARTICLE INFO}

Research Article $\quad$ DOI: 10.15832 /ankutbd.456649

Corresponding Author: İbrahim Savaş DALMIȘ, E-mail: idalmis@nku.edu.tr, Tel: +90 (282) 2502345

Received: 13 April 2017, Received in Revised Form: 17 June 2017, Accepted: 30 June 2017

\begin{abstract}
In this research, a prototype downdraft throatless gasifier was designed with a mechanical stirrer. The gasifier was designed for gasification of rice straw pellets. The diameter of the reactor was $350 \mathrm{~mm}$ and a nominal value for the heat power of biomass input was $70 \mathrm{~kW}$. Rice straws which were collected from Thrace Region of Turkey gasified for determination of the designed gasifier performance in Namik Kemal University Biosystem Engineering Laboratories. The effects of airflow path and stirring process on the gasification efficiency during the gasification process were investigated. Temperatures and airflow rates observed and adjusted by controlling the air flow rate in the automation system constantly. Pellets were gasified using two different airflow paths with the same equivalence ratio of 0.2 and these were compared. Air inlet from the top showed better results than air inlet from tuyeres. For the air inlet from the top, the higher heating value of producer gas was determined as $5.047 \mathrm{MJ} \mathrm{Nm}^{-3}$ and cold gas efficiency was calculated as $65.4 \%$. $\mathrm{H}_{2} / \mathrm{CO}$ ratio was found as 1.385 which was higher than the air inlet from tuyeres.

Keywords: Biomass gasification; Rice straw; Stirrer; Throatless; Downdraft; Gasifier design
\end{abstract}

(C) Ankara Üniversitesi Ziraat Fakültesi

\section{Introduction}

One of the most controversial topics in the world is global climate change caused by $\mathrm{CO}_{2}$ emissions. Therefore, greener energy sources have become significant alternatives to current energy resources and the number of the works being carried out on renewable energy has increased in current years. Biomass is one of the renewable energy sources which inspires interest for researchers (Anis \& Zainal 2011). Fossil fuel resources are gradually decreasing causing the cost of petroleum-based products to increase. This problem imposes a need for an equipment that can produce an alternative source of fuel (Manguiat et al 2015). Biomass gasification occurs as a thermochemical process to produce gaseous fuel from carbonaceous feedstock which are included but not limited to pinewood, 
eucalyptus wood, wheat straw, rice straw, rice husk, corn cob, corn stalk, sugarcane bagasse, poplar, hazelnut shell, coconut shell, switch grass, olive husk and so on (Demirbas 2004; Mondal et al 2011; Nwokolo et al 2016). Producer gas consists of carbon monoxide, hydrogen, carbon dioxide, methane, traces of higher hydrocarbons, such as ethane and ethylene, water vapor, nitrogen (if air is the oxidizing agent), and various contaminants, such as small char particles, ash, tar and oil (Basu 2013).

A review of the 50 gasifier manufacturers in Europe, United States, Canada showed that $75 \%$ of the designs were downdraft fixed beds while fluidized beds, updraft fixed beds and the other designs were $20 \%, 2.5 \%, 2.5 \%$, respectively (Balat et al 2009; Zhang et al 2015).

Ma et al (2012) presented a systematic design and experimental results of a $190 \mathrm{kWe}$ biomass fixed bed gasification and poly-generation pilot plant using a double air stage downdraft approach. They used a mechanical stirrer, secondary air supply, and wood chips as feedstock. It was reported that due to the secondary air supply, an enhanced tar cracking was achieved by increasing the temperature as high as $900{ }^{\circ} \mathrm{C}$ in the oxidation zone. Bridging and channelling were avoided by the use of both stirrer and reciprocating grate. In their research, the stirrer was placed in the drying zone of the reactor. The difference of our work is that the stirrer was placed in the combustion zone of the reactor.

Jain \& Goss (2000) designed and fabricated four open core throatless batch fed rice husk gasifier reactors having internal diameters of 15.2, 20.3, 24.4 and $34.3 \mathrm{~cm}$. Each reactor connected to a gas cleaning unit was tested for its performance characteristics. On each reactor, ten trial runs were conducted by varying the air flow rate or specific gasification rate. An experimental investigation in a downdraft gasifier was carried out by Striūgas et al (2014). They used different types of fuel and waste for a comparison of process performances and estimation of the potential to gasify various feedstock types in a single fully automated device. A number of different feedstock, including wood chips, pellets from wood, rape straw, poultry litter, dried sewage sludge and their mix with wood, were used for the investigation. The process efficiencies associated with the gasification of various feedstock and the effect of process parameters, such as temperature, pressure drop of a bed, product composition and output on the process were reported.

A review article on biomass gasification models for downdraft gasifier has recently been contributed by Patra \& Sheth (2015). In the review, the importance of modeling for biomass gasification was explained and different models available for downdraft gasifiers were discussed and evaluated. The main focus was the equilibrium models for both fluidized bed and downdraft gasifiers.

In a typical design of the downdraft reactor, the biomass is fed from the top of the reactor and moves downwards as a result of its conversion and the removal of ashes through a grate at the bottom of the reactor. The literature review shows that gasification of different biomass in downdraft gasifiers entails certain difficulties with a lack of literature about the gasifier with a mechanical stirrer. Therefore, the main objective of this study was to perform experimental investigations of gasification process in the designed prototype downdraft gasifier using rice straw pellets to determine process performance and estimate the feasibility of gasification of pure rice straw pellets.

\section{Material and Methods}

In this research, a prototype gasifier system with an overhead controlled mechanical stirrer was designed for rice straw pellets gasification. In this section, biomass characteristics, experimental setup, and experimental procedure will be explained.

\subsection{Biomass characteristics}

Rice straws collected from Thrace Region of Turkey were pelleted in a firm located in Tekirdağ. Mean diameter of pellets was $6.2 \mathrm{~mm}$ and the mean length was $53.6 \mathrm{~mm}$. Mean bulk density $\left(\rho_{\mathrm{b}}\right)$ and unit density $\left(\rho_{\mathrm{u}}\right)$ values of pellets were $562.3 \mathrm{~kg} \mathrm{~m}^{-3}$ 
and $1226.4 \mathrm{~kg} \mathrm{~m}^{-3}$, respectively (EN 15103 - 2009). Table 1 shows proximate analysis results for dry basis, original basis, and ultimate analysis results.

Table 1- Proximate and ultimate analysis of rice straw

\begin{tabular}{lccc}
\hline \multicolumn{4}{l}{ Proximate analysis $(\%, w t)$} \\
\hline Moisture & 7.01 & - & $7582-12$ \\
Volatile matter & 61.61 & 66.25 & $7582-12$ \\
Fixed carbon & 14.18 & 15.24 & $3172-13$ \\
Ash & 17.21 & 18.50 & $1755-01$ \\
Ultimate analysis $(\%, w t)$ & & Standard $($ ASTM D) \\
\hline $\mathrm{C}$ & 39.90 & & $5373-14$ \\
$\mathrm{H}$ & 4.89 & & $5373-14$ \\
$\mathrm{O}$ & 35.27 & & $3176-09$ \\
$\mathrm{~N}$ & 1.24 & & $5373-14$ \\
$\mathrm{~S}$ & 0.20 & & $4239-14$ \\
\hline
\end{tabular}

Determined lower heating value of biomass pellets $\left(\mathrm{LHV}_{\mathrm{F}}\right)$ for original basis and dry basis were 12.77 $\mathrm{MJ} \mathrm{kg}^{-1}$ and $13.90 \mathrm{MJ} \mathrm{kg}^{-1}$, respectively. Also, the higher heating values $\left(\mathrm{HHV}_{\mathrm{F}}\right)$ were $13.84 \mathrm{MJ}$ $\mathrm{kg}^{-1}$ original basis and $14.89 \mathrm{MJ} \mathrm{kg}^{-1}$ for dry basis (ASTM D 5865-13). First deformation temperature, softening temperature and hemisphere temperature (ASTM D 1857/D1857) were $1045{ }^{\circ} \mathrm{C}, 1239{ }^{\circ} \mathrm{C}$, and $1436{ }^{\circ} \mathrm{C}$, respectively. A sample of rice straw pellets used in this study as biomass fuel is shown in Figure 1.
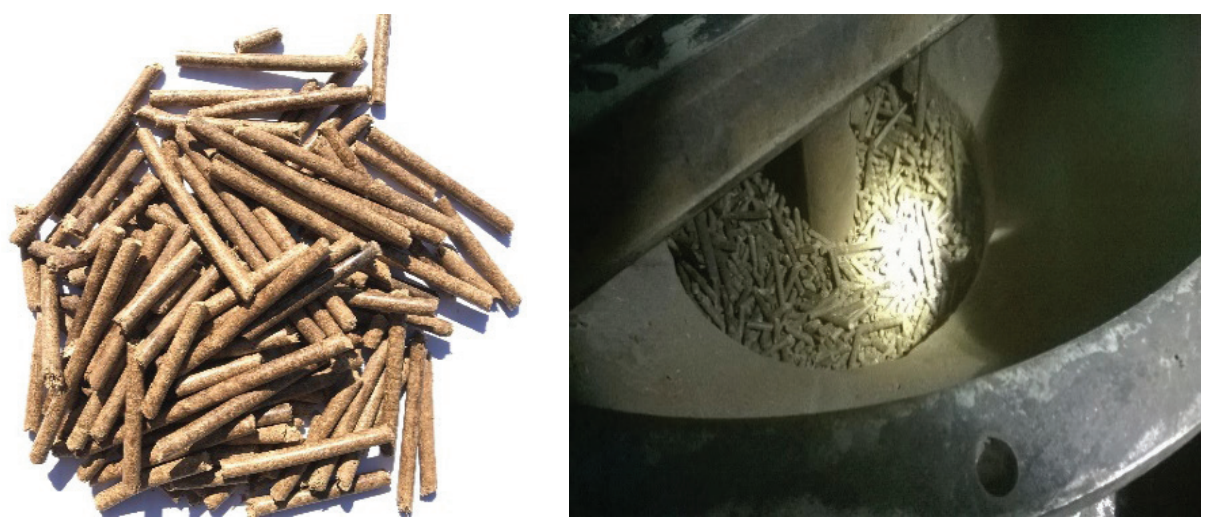

Figure 1- Rice straw pellets

\subsection{Experimental setup}

A downdraft biomass gasifier was designed for rice straw pellet gasification. Characteristic parameters of the design are given in Table 2. Air was used as gasification agent. Design of gasifier allowed working with two different airflow inlets; from the top and from the tuyeres. An overhead activated mechanical stirrer was added to the reactor to determine the effects of stirring.

Table 2- Characteristic parameters of the designed gasifier

\begin{tabular}{|c|c|}
\hline Type of reactor & Fixed bed, downdraft, throatless \\
\hline Diameter & $350 \mathrm{~mm}$ \\
\hline Refractor layer & Yes $(50 \mathrm{~mm})$ \\
\hline Tuyeres & 10 items (Diameter $7.8 \mathrm{~mm}$ ) \\
\hline Fuel feeding & Manual (Batch type) \\
\hline Grid & No \\
\hline Ash removal & Semi-automatic control (HMI panel) \\
\hline $\begin{array}{l}\text { Fuel } \\
\text { consumption }\end{array}$ & $\begin{array}{l}19 \pm 1 \mathrm{~kg} \mathrm{~h}^{-1} \text { (for SGR } 200 \pm 10 \mathrm{~kg} \mathrm{~h}^{-1} \\
\mathrm{~m}^{-2} \text { ) }\end{array}$ \\
\hline $\begin{array}{l}\text { Power input } \\
\text { (biomass) }\end{array}$ & $70 \mathrm{~kW}$ (for FCR $20 \mathrm{~kg} \mathrm{~h}^{-1}$ ) \\
\hline
\end{tabular}

Experimental setup consisted of gasifier reactor, cyclone, gas cooling unit and condensation tank, vacuum pump and service water tank, flare unit, measurement and control components, gas chromatography device and its components. General

\section{Figure 1- Rice straw pellets}

Tarım Bilimleri Dergisi - Journal of Agricultural Sciences $\quad 24$ (2018) 329-339 
view of the system is shown in Figure 2 and flow chart is given in Figure 3.

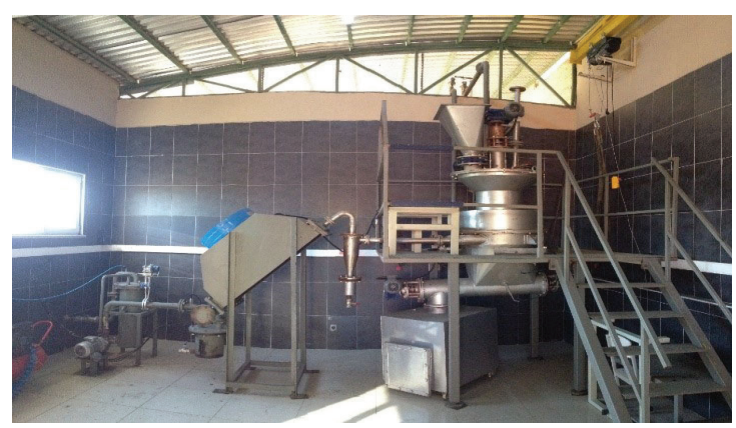

Figure 2- General view of gasifier system

\subsubsection{Gasifier}

The stratified design has some advantages over the throated design. The cylindrical construction is easy to manufacture and allows continuous flow of troublesome fuels without causing bridging and channeling (Reed \& Das 1988).

The diameter of the reactor $\left(D_{R}\right)$ was calculated by using Equation 1 and determined as 0.350 m. Specific gasification rate $(S G R)$ and fuel consumption rate $(F C R)$ were assumed as $200 \mathrm{~kg}$ $\mathrm{m}^{-2} \mathrm{~h}^{-1}$ (Jain 2006) and $20 \mathrm{~kg} \mathrm{~h}^{-1}$, respectively. Other main dimensions of reactor body are shown in Figure 4.

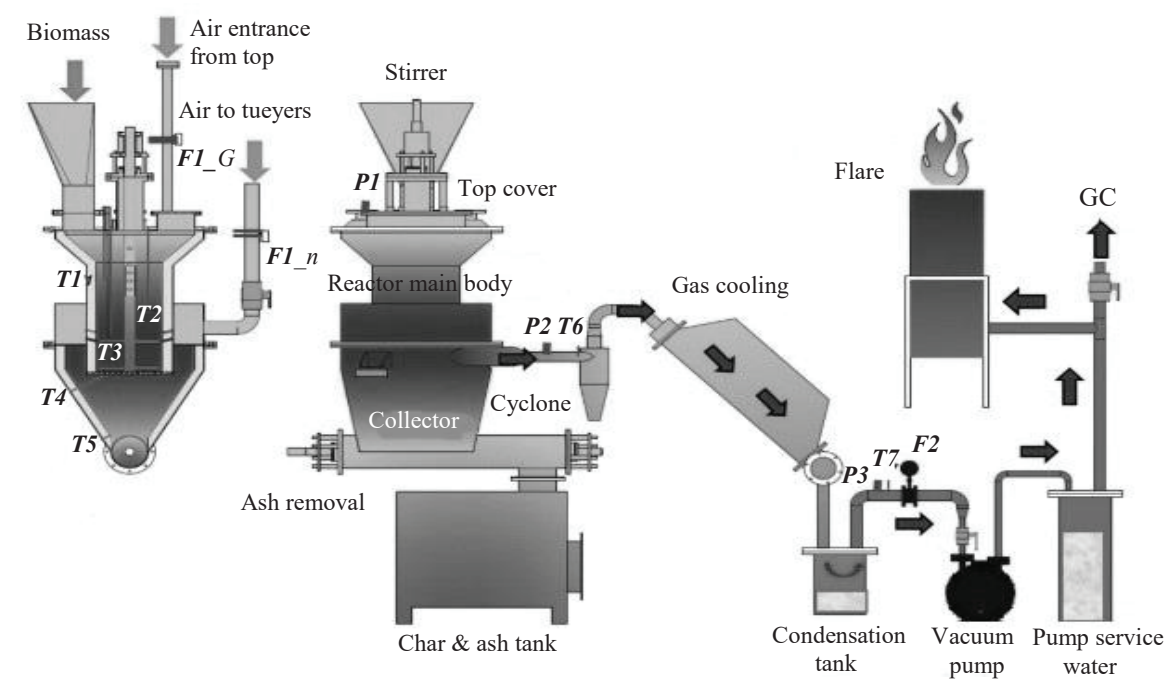

Figure 3- Flow chart of the gasification system

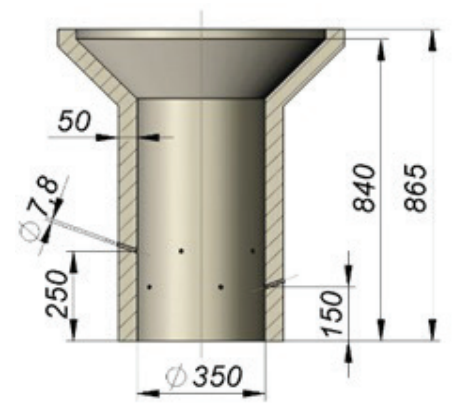

$$
D_{R}=\sqrt{\frac{4 \cdot F C R}{\pi \cdot S G R}}
$$

Minimum height of the reactor $\left(H_{R}\right)$ needed was calculated from Equation 2 and determined as 0.74 $\mathrm{m}$ for the operation lasting two hours. It was taken $0.84 \mathrm{~m}$ for safety.

$$
H_{R}=\frac{F C R \cdot t}{A_{R} \cdot \rho_{b}}
$$

Figure 4- Main reactor body dimensions 
Heating power of biomass $\left(P_{F}\right)$ was determined by using Equation 3 and found about $70 \mathrm{~kW}$ while the $F C R$ was $20 \mathrm{~kg} \mathrm{~h}^{-1}$ and the $L H V_{F}$ was $12.77 \mathrm{MJ} \mathrm{kg}^{-1}$.

$P_{F}=L H V_{F} \cdot F C R \cdot \frac{1}{3.6}$

Gasifier was designed as downdraft, fixed bed, and throatless type. The general structure included 4 units; top unit, main body, collector and ash removal unit, char and ash storage unit.

AISI 310 was selected as a construction material for the main body to overcome the corrosion problems while working at high temperatures. AISI 310 can work continuously at $1150{ }^{\circ} \mathrm{C}$ without corrosion. Reactor inner wall was constructed with refractive material to save main steel body from hightemperature effects. The thickness of refractive layer was applied as $50 \mathrm{~mm}$. It was also used to overcome the adhesion problems of possible vitrified biomass to inner walls. Hycast 70 was used as a refractive material which can be used up to $1500{ }^{\circ} \mathrm{C}$

Bridging can be prevented by stirring, shaking, or agitating the bed (Reed \& Das 1988). Related dimensions are shown in Figure 5. The aim of using the stirrer was to decrease the temperatures whenever needed and to reduce the effects of agglomeration that may occur during the gasification process.

The position of the stirrer was adjustable along the reactor axis. The stirrer was overhead controlled by an electric motor that had $0.55 \mathrm{~kW}$ power. Rotational speed was adjustable by an inverter control placed on the human-machine interface (HMI) panel.

\subsubsection{Measurement and control}

Measurements made from 7 points for temperature, from 3 points for pressure, from 2 points for flow rate. Data monitoring and system control were operated by PLC and HMI control panel.

7 K-type thermocouples (Jain 2006) were used totally; 5 for reactor temperature profile, 1 for gas exit temperature and 1 for gas temperature after cooling. Figure 6 shows the positions of first 5 thermocouples along the rector height.

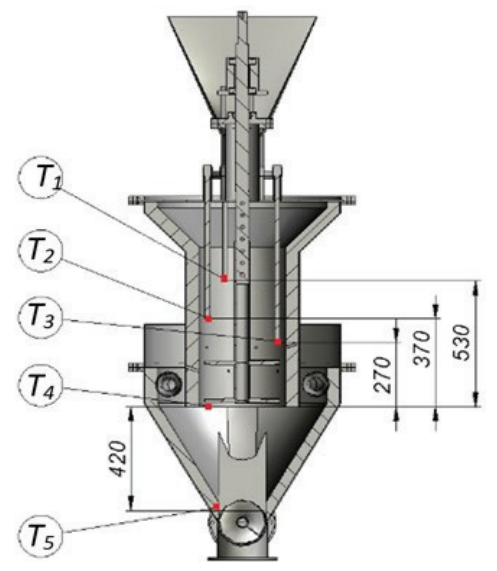

Figure 6- Thermocouple positions on reactor

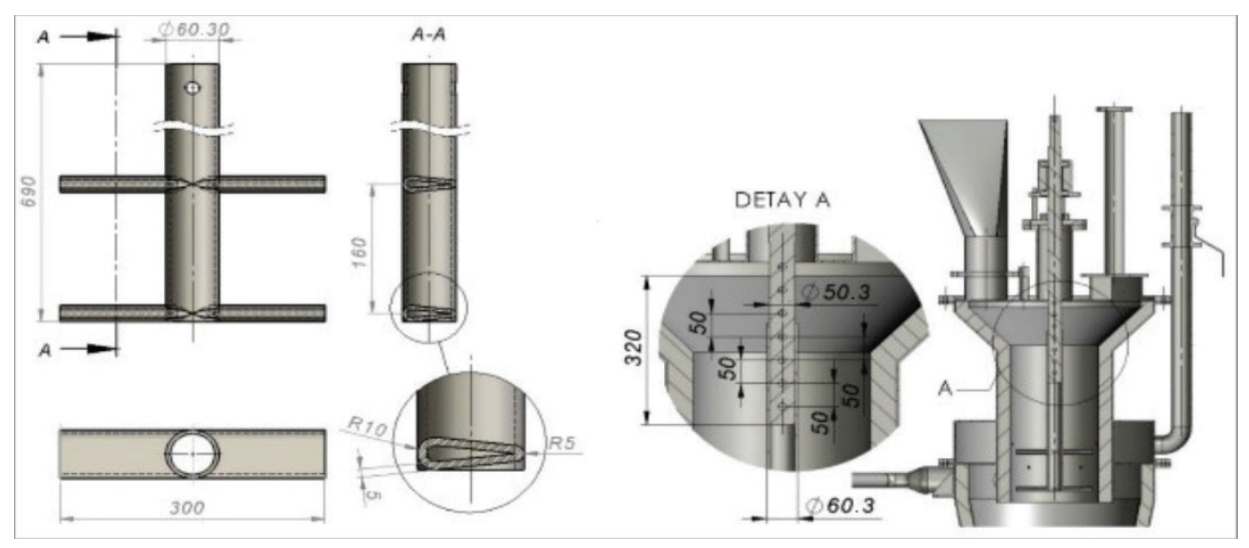

Figure 5- Stirrer construction and main dimensions 
3 pressure transmitters were used in the system. $\mathrm{P}_{1}$ was placed under the cover part of reactor body, $\mathrm{P}_{2}$ on gas exit pipe and $\mathrm{P}_{3}$ on the pipe after cooling. The measurable range of selected transmitters was \pm 1 bar.

The flow rate for the producer gas was measured by an orifice flow meter which had its own indicator with LED screen. It was suitable for the temperatures up to $200{ }^{\circ} \mathrm{C}$. Air flow rate was also measured by an orifice flow meter that works together with a pressure differential transmitter.

Power of electric motor vacuum pump was $1.5 \mathrm{~kW}$ and it was controllable by an inverter. Additionally, three more motors were used to activate the stirrer, ash removal helix, and cooler fan. Each of these three components had the power of $0.55 \mathrm{~kW}$. The stirrer motor was also controlled by an inverter. All on/off and invertor controls of the motors were on the control panel. Control panel included shelters, PLC modules, and HMI. HMI was 7" and connected to a computer via Ethernet. The data was stored via USB port.

\subsubsection{Gas analysis}

Agilent 7890B GC model gas chromatography device was used to analyze the composition of producer gas. $\mathrm{CO}, \mathrm{H}_{2}, \mathrm{CH}_{4}, \mathrm{CO}_{2}$ and $\mathrm{N}_{2}$ concentrations were determined as volumetric percentages. In the experiments, 3 gas examples were taken in one experiment cycle time for each airflow path. One experiment cycle lasted for 1-1.5 hours. Gas sampling line was separated from the main line after flow measurement. High-purity argon gas was used as a gas carrier for sampling process.

\subsection{Experimental procedure}

The experiments were done for two different airflow paths with the same equivalence of ratio 0.2. The airflow paths that explained below are shown in Figure 7.

Airflow path 1 (AFP_1): Air comes into the reactor from the top, passing through the biomass bed, arrives reacting and inert char zones and leaves gasifier.

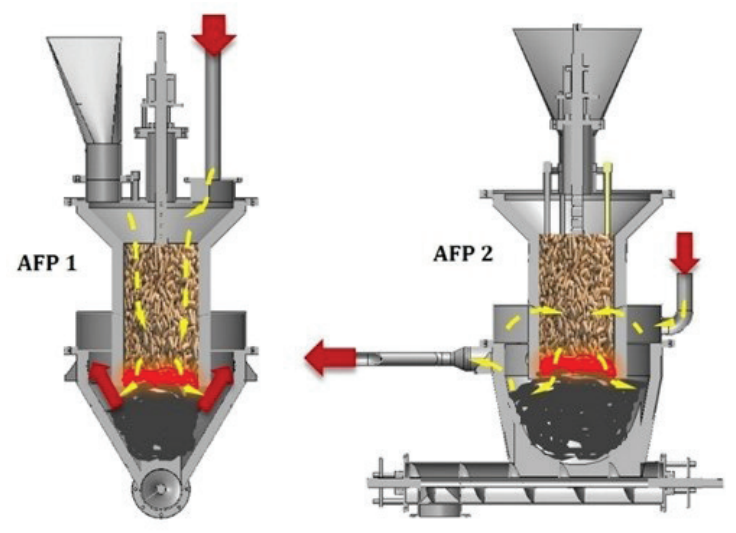

Figure 7- The airflow paths used in experiments

Airflow path 2 (AFP_2): Air comes into the reactor from the tueyers, moves through the oxidation and reduction zones and leaves gasifier.

\subsubsection{Preparation}

Collector was filled up to the grid level with charash mixture remained from previous applications. 5 $\mathrm{kg}$ pellets were placed on this char bed and fired by the help of some wood pieces. For the first step, both air inlets were kept open. When the flames arrived at the top level, $25 \mathrm{~kg}$ fuel was loaded into the reactor and the cover was closed. According to selected air path and airflow rate, air inlets were adjusted by the valves and inverter controls on HMI screen panel. After setting was completed, the experiment started.

The experiments' finish times were determined by observation of the flame level of the reactor. The observation was made by opening the valve on the biomass storage bunker. The finish times of experiments were obtained when the flame arrived at the top level of loaded biomass. During the experiment, parameters such as time, temperatures, pressures and flow rates were observed on the screen of the control panel and the data was recorded via a USB port on the panel.

The stirrer was activated when the temperature exceeded $800{ }^{\circ} \mathrm{C}$. In other cases, the stirrer was not activated. The reactor was also tested without the stirrer by disassembly of the stirrer from the reactor. 


\subsubsection{Calculations}

Stoichiometric ratio (SR): Stoichiometric air needed for full combustion was calculated according to ultimate analysis results by Equation 4 (Zhu \& Venderbosch 2005). $\mathrm{C}_{\mathrm{C}}, \mathrm{C}_{\mathrm{H}}, \mathrm{C}_{\mathrm{O}}$ and $\mathrm{C}_{\mathrm{A}}$ mean the percentages of carbon, hydrogen, oxygen, and ash respectively given with ultimate analysis of biomass. SR value was determined as $3.856 \mathrm{~kg}$ air for $1 \mathrm{~kg}$ fuel.

$S R=\left(\frac{C_{C}}{12}+\frac{C_{H}}{4}-\frac{C_{O}}{32}\right) \cdot\left(1+\frac{79}{21}\right) \cdot\left(1-\frac{C_{A}}{100}\right) \cdot \frac{28.84}{100}$

FCR $\left(\mathrm{kg} \mathrm{h}^{-1}\right)$ was calculated by Equation 5 . The term $m_{\mathrm{B}}$ is defined as the mass of biomass fuel $(\mathrm{kg})$ for one experiment and $t$ is the measured experiment time (h).

$F C R=\frac{m_{B}}{t}$

Equivalence ratio $(E R)$ : Equation 6 was used to calculate ER (Reed \& Das 1988). AFR is airflow rate measured $\left(\mathrm{m}^{3} \mathrm{~h}^{-1}\right)$ and $S R_{V}$ is stoichiometric air volume for $1 \mathrm{~kg}$ of biomass fuel $\left(\mathrm{m}^{3} \mathrm{~kg}^{-1}\right)$ under experiment conditions. $\mathrm{SR}_{\mathrm{V}}$ was taken as $3.257 \mathrm{~m}^{3}$ air at $25^{\circ} \mathrm{C}$ and $1 \mathrm{~atm}$ pressure.

$E R=\frac{A F R}{F C R \cdot S R_{V}}$

$S G R\left(\mathrm{~kg} \mathrm{~h}^{-1} \mathrm{~m}^{-2}\right)$ is the fuel consumption rate per unit area of the reactor $\left(\mathrm{m}^{2}\right)$ (Tiangco et al 1996). Equation 7 was used to calculate SGR.

$S G R=\frac{F C R}{A_{R}}$

Specific gas production rate (SGPR): SGPR (N $\left.\mathrm{m}^{3} \mathrm{~m}^{-2} \mathrm{~h}^{-1}\right)$ is the producer gas flow rate $(G F R)$ per unit area of reactor that calculated with Equation 8.

$S G P R=\frac{G F R}{A_{R}}$

$L H V_{G}\left(\mathrm{MJ} \mathrm{Nm}^{-3}\right)$ was the lower heating value of producer gas that was calculated by Equation (9) and $H H V_{G}\left(\mathrm{MJ} \mathrm{Nm}^{-3}\right)$ is the higher heating value of gas that was calculated by Equation (10). In these equations, it is clear that the gas compounds affected the gas calorific value are $\mathrm{H}_{2}, \mathrm{CO}$, and $\mathrm{CH}_{4}$ (Waldheim \& Nilsson 2001).

$$
\begin{aligned}
& L H V_{G}=10.8 \cdot \% H_{2}+12.63 \cdot \% C O+35.8 \cdot \% C H_{4} \\
& H H V_{G}=12.76 \cdot \% H_{2}+12.63 \cdot \% C O+39.75 \cdot \% C_{4}
\end{aligned}
$$

$P_{G}(\mathrm{~kW})$ is the thermal power of producer gas that calculated with Equation 11. $L H V_{G}\left(\mathrm{MJ} \mathrm{Nm}^{-3}\right)$ and GFR $\left(\mathrm{Nm}^{3} \mathrm{~h}^{-1}\right)$.

$$
P_{G}=L H V_{G} \cdot G F R \cdot \frac{1}{3.6}
$$

Cold gas efficiency $\left(\eta_{C G}\right)$ equation is given with Equation 12.

$$
\eta_{C G}=\frac{P_{F}}{P_{G}} \cdot 100 \%
$$

\section{Results and Discussion}

In this section, producer gas compositions, gasifier performance and the temperature profiles of the reactor were evaluated and compared for both airflow paths.

\subsection{Gas compositions}

Gas compositions and calculated lower and higher heating values are shown in Table 3 . The LHV and HHV values presented in Table 3 are the values between the highest and the lowest values obtained according to the gas analysis results. As it is seen that the heating values were very close to each other but hydrogen/carbon monoxide rate was remarkably different. The $\mathrm{H}_{2} / \mathrm{CO}$ value was desired as high as possible for environmental aspects. For this purpose, AFP_1 with the values of $5.047 \mathrm{MJ} \mathrm{Nm}^{-3}$ and 1.385 was preferred for $\mathrm{HHV}$ and $\mathrm{H}_{2} / \mathrm{CO}$ respectively. In calculations, the value in the middle of the measured heating values was used. 
Table 3- Producer gas compositions and heating values for AFP_1 and AFP_2

\begin{tabular}{|c|c|c|c|c|c|c|}
\hline \multirow{2}{*}{$\begin{array}{l}\text { Airflow } \\
\text { path }\end{array}$} & \multicolumn{3}{|c|}{ Gas compositions (\%) } & \multirow{2}{*}{$L H V\left(M J N^{-3}\right)$} & \multirow{2}{*}{$H H V\left(M J m^{-3}\right)$} & \multirow{2}{*}{$\mathrm{H}_{2}(\%) / \mathrm{CO}(\%)$} \\
\hline & $\mathrm{H}_{2}$ & $\mathrm{CO}$ & $\mathrm{CH}_{4}$ & & & \\
\hline $\begin{array}{c}\text { AFP_1 } \\
\text { (from the top) }\end{array}$ & 18.25 & 13.18 & 2.65 & 4.584 & 5.047 & 1.385 \\
\hline $\begin{array}{c}\text { AFP_2 } \\
\text { (from tueyers) }\end{array}$ & 15.19 & 16.45 & 2.20 & 4.506 & 4.890 & 0.923 \\
\hline
\end{tabular}

\subsection{Gasifier performance}

Performance characteristics such as FCR, SGR, GFR, SGPR, $P_{F}, P_{G}$ and $\eta_{\mathrm{CG}}$ are given in Table 4. It is clearly seen that $\mathrm{AFP}_{-} 1$ was preferable because of its cold gas efficiency value of $65.4 \%$ which is an acceptable value for a biomass gasifier. This result is in good agreement with previous publications. The previous researches on the evaluation of the energy content of paddy waste by gasification focused mostly on using rice husk as biomass feedstock due to fuel preparation cost like shredding and pelletizing.

Table 4- Gasifier performance characteristics for AFP_1 and AFP_2

\begin{tabular}{cccccccc}
\hline $\begin{array}{c}\text { Airflow } \\
\text { path }\end{array}$ & $\begin{array}{c}F C R \\
\left(\mathrm{~kg} \mathrm{~h} \mathrm{~h}^{-1}\right)\end{array}$ & $\begin{array}{c}S G R \\
\left(\mathrm{~kg} \mathrm{~h}^{-1} \mathrm{~m}^{-2}\right)\end{array}$ & $\begin{array}{c}G F R \\
\left(\mathrm{Nm}^{3} \mathrm{~h}^{-1}\right)\end{array}$ & $\begin{array}{c}S G P R \\
\left(\mathrm{Nm}^{3} \mathrm{~h}^{-1} \mathrm{~m}^{-2}\right)\end{array}$ & $\begin{array}{c}P_{F} \\
(\mathrm{~kW})\end{array}$ & $\begin{array}{c}P_{G} \\
(\mathrm{~kW})\end{array}$ & $\eta_{C G}(\%)$ \\
\hline $\begin{array}{c}\text { AFP_1 } \\
\text { (from the top) } \\
\begin{array}{c}\text { AFP_2 } \\
\text { (from tueyers) }\end{array}\end{array}$ & 19.8 & 205.8 & 36.1 & 375.2 & 70.2 & 46.0 & 65.5 \\
\hline
\end{tabular}

Jain \& Goss (2000) studied the optimum values of SGR, $\mathrm{LHV}_{\mathrm{g}}$ and gasification efficiency for rice husk gasification and they reported the gasification efficiency value of $65 \%$ for their gasifier under optimum conditions.

Yoon et al (2012) reported that they conducted the gasification process under the temperature range $600-850{ }^{\circ} \mathrm{C}$ with the excess air ratio of 0.2-0.32 for rice husk pellets. They determined that they reached the cold gas efficiency value of $70 \%$.

The size of the mechanical stirrer caused the formation of a temperature bridge between the combustion and the drying zones in the reactor. In addition to this, the system was destabilized with the rapid movement of the combustion zone towards the drying zone. This situation affected the efficiency of the gasification system by shortening the time.

\subsection{Temperature profiles}

AFP_1 was more efficient than AFP_2 hence only AFP_1 was used in the experiments without mechanical stirrer. Measured temperatures are given in Table 5. Temperature profiles given in Figure 8 were obtained from the data saved from the first five thermocouples placed on the reactor body.

Table 5- Temperature distribution for AFP_1, AFP_ 2 and AFP_1 (without stirrer)

$A F P_{-} 1 \quad A F P \_2 \quad A F P_{-} 1$

Temperature (from the top) (from tueyers) (without stirrer)

\begin{tabular}{cccc} 
& $\left({ }^{\circ} \mathrm{C}\right)$ & $\left({ }^{\circ} \mathrm{C}\right)$ & $\left({ }^{\circ} \mathrm{C}\right)$ \\
\hline $\mathrm{T} 1$ & 41 & 63 & 23 \\
$\mathrm{~T} 2$ & 44 & 44 & 21 \\
$\mathrm{~T} 3$ & 73 & 87 & 23 \\
$\mathrm{~T} 4$ & 705 & 687 & 746 \\
$\mathrm{~T} 5$ & 66 & 46 & 187 \\
\hline
\end{tabular}




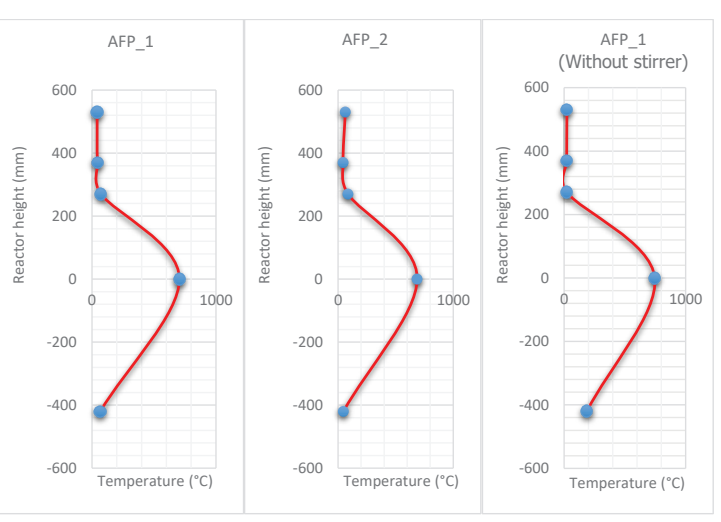

Figure 8- Temperature profiles of reactor for AFP_1, AFP_2 and AFP_1 (without stirrer)

Maximum temperature value of the reactor was $746^{\circ} \mathrm{C}$ and no vitrification observed under the experiment conditions. This observation is in well agreement with a previous publication by Lin et al (1998). Their observation was that the gasification temperatures under $1000 \mathrm{~K}$ would recover amorphous silica materials.
The shaft of stirrer behaved like a heat bridge and took the heat from the core region to the upper cover of the reactor. In AFP_1, the fresh air that came from upside cooled down the upper regions.

\subsection{Comparison of the gasifier performance due to the stirrer effect}

In the experiments, it was determined that AFP_1 was more efficient than AFP_2 hence only AFP_1 was used in the experiments without mechanical stirrer.

Gas compositions and calculated lower and higher heating values are shown in Table 6. Although the results were very close to each other, using the reactor without stirrer could be more preferable when considering reactor manufacturing costs in addition to the results.

Performance characteristics such as FCR, SGR, GFR, SGPR, PF, PPG and $\eta_{\mathrm{CG}}$ are given in Table 7. It can be seen that the gasification efficiencies for both applications were very close to each other.

Table 6- Producer gas compositions and heating values for AFP_1 (with and without stirrer)

\begin{tabular}{|c|c|c|c|c|c|c|}
\hline \multirow{2}{*}{$\begin{array}{l}\text { Airflow } \\
\text { path }\end{array}$} & \multicolumn{3}{|c|}{ Gas compositions (\%) } & \multirow{2}{*}{$L H V\left(M J N^{-3}\right)$} & \multirow{2}{*}{$H H V\left(M J N^{-3}\right)$} & \multirow{2}{*}{$\mathrm{H}_{2}(\%) / \mathrm{CO}(\%)$} \\
\hline & $\mathrm{H}_{2}$ & $\mathrm{CO}$ & $\mathrm{CH}_{4}$ & & & \\
\hline $\begin{array}{c}\text { AFP_1 } \\
\text { (with stirrer) }\end{array}$ & 18.25 & 13.18 & 2.65 & 4.584 & 5.047 & 1.385 \\
\hline $\begin{array}{c}\text { AFP_1 } \\
\text { (without stirrer) }\end{array}$ & 18.22 & 12.91 & 2.66 & 4.550 & 5.013 & 1.411 \\
\hline
\end{tabular}

Table 7- Gasifier performance characteristics for AFP_1 (with and without stirrer)

\begin{tabular}{cccccccc}
\hline $\begin{array}{c}\text { Airflow } \\
\text { path }\end{array}$ & $\begin{array}{c}F C R \\
(\mathrm{~kg} \mathrm{~h})\end{array}$ & $\begin{array}{c}S G R \\
\left(\mathrm{~kg} \mathrm{~h} \mathrm{~h}^{-1}\right)\end{array}$ & $\begin{array}{c}G F R \\
\left(\mathrm{Nm}^{3} \mathrm{~h}^{-1}\right)\end{array}$ & $\begin{array}{c}S G P R \\
\left(\mathrm{Nm}^{3} \mathrm{~h}^{-1} \mathrm{~m}^{-2}\right)\end{array}$ & $\begin{array}{c}P_{F} \\
(\mathrm{~kW})\end{array}$ & $\begin{array}{c}P_{G} \\
(\mathrm{~kW})\end{array}$ & $\eta_{C G}(\%)$ \\
\hline $\begin{array}{c}\text { AFP_1 } \\
\text { (with stirrer) }\end{array}$ & 19.8 & 205.8 & 36.1 & 375.2 & 70.2 & 46.0 & 65.5 \\
$\begin{array}{c}\text { AFP_1 } \\
\text { (without stirrer) }\end{array}$ & 19.5 & 202.7 & 35.9 & 373.1 & 69.1 & 45.8 & 65.6 \\
\hline
\end{tabular}

\section{Conclusions}

The designed gasifier for rice straw pellets successfully worked. The designed system allowed to generate clean producer gas which can be used for heating processes. The vitrification could be taken under control with designed system. In case of using additional cleaning and filtering components, electrical power generation would also be possible.

Equivalence ratio was applied as 0.2 for experiments. Two different airflow paths were tested 
with this equivalence ratio and compared for the process. AFP_1 had higher cold gas efficiency than AFP_2. Furthermore, the $\mathrm{H}_{2} / \mathrm{CO}$ value of AFP_1 was higher than that of AFP_2.

Activation of the stirrer caused a decrease in the temperature and helped to take them under control which can be considered as an advantage. On the other hand, the existence of an overhead driven stirrer axe generated a disadvantage by acting like a heat bridge between reaction zones and driving them away from the steady state. Therefore, using the overhead driven stirrer was unadvisable for rice straw gasification due to the risks for vitrification and steady-state points of view.

\section{Acknowledgements}

We would like to thank TUBITAK for the supporting this project that numbered 113O434. The experimental gasifier laboratory established by this TUBITAK Project.

\begin{tabular}{|ll|}
\hline Abbreviations and Symbols \\
\hline$D_{R}$ & Diameter of reactor \\
$S G R$ & Specific gasification rate \\
$F C R$ & Fuel consumption rate \\
$H_{R}$ & Height of the reactor \\
$P_{F}$ & Heating power of biomass \\
$L H V$ & Lower heating values \\
$H H V$ & Higher heating values \\
$S R$ & Stoichiometric ratio \\
$C_{C}$ & Percentages of carbon \\
$C_{H}$ & Percentages of hydrogen \\
$C_{O}$ & Percentages of oxygen \\
$C_{A}$ & Percentages of ash \\
$m_{B}$ & Mass of biomass fuel \\
$t$ & Measured experiment time \\
$E R$ & Equivalence ratio \\
$A F R$ & Airflow rate \\
$S R$ & Stoichiometric air volume \\
$P_{G}$ & Thermal power of producer gas \\
$S G P R$ & Specific Gas Production Rate \\
$G F R$ & Producer gas flowrate \\
$A_{R}$ & Area of reactor \\
$\eta_{C G}$ & Cold gas efficiency \\
$A F P$ & Airflow path \\
$\rho_{b}$ & Bulk density of biomass \\
\hline
\end{tabular}

\section{References}

Anis S \& Zainal Z A (2011). Tar reduction in biomass producer gas via mechanical, catalytic and thermal methods: A review. Renewable and Sustainable Energy Reviews 15(5): 2355-2377

Anonymous (2017). Kiltas Refractory Materials Industry Inc. Refractory Materials, Concretes, Hycast ${ }^{\circledR} 70$. Retrieved in March, 25, 2017, from http://www.kiltas. com.tr

Balat M, Balat M, Kirtay E \& Balat H (2009). Main routes for the thermo-conversion of biomass into fuels and chemicals. Part 2: Gasification systems. Energy Conversion and Management 50(12): 3158-3168

Basu P (2013). Biomass gasification, pyrolysis and torrefaction: Practical design and theory. Academic press. ISBN 978-0-12-396488

Demirbas A (2004). Combustion characteristics of different biomass fuels. Progress in Energy and Combustion Science 30(2): 219-230

Jain A K (2006). Design parameters for a rice husk throatless gasifier. Agricultural Engineering International: The CIGR Ejournal 8: Manuscript EE 05012

Jain A K \& Goss J R (2000). Determination of reactor scaling factors for throatless rice husk gasifier. Biomass and Bioenergy 18(3): 249-256

Lin S K, Wang H P, Lin C J \& Juch C (1998). A process development for gasification of rice husk. Fuel Processing Technology 55(3): 185-192

Ma Z, Zhang Y, Zhang Q, Qu Y, Zhou J \& Qin H (2012). Design and experimental investigation of a $190 \mathrm{~kW}$ e biomass fixed bed gasification and polygeneration pilot plant using a double air stage downdraft approach. Energy 46(1): 140-147

Manguiat N A S, Marco O C, Miranda C M N, Moren K O \& Magnaye R L R R C (2015). Design and development of a wood-fired gasifier prototype for synthesis gas production and analysis. Asia Pacific Journal of Multidisciplinary Research 3(5): 160-166

Mondal P, Dang G S \& Garg M O (2011). Syngas production through gasification and cleanup for downstream applications-recent developments. Fuel Processing Technology 92(8): 1395-1410

Nwokolo N, Mamphweli S \& Makaka G (2016). An investigation into heat recovery from the surface of a cyclone dust collector attached to a downdraft 
biomass gasifier. Applied Thermal Engineering 98: $1158-1164$

Patra T K \& Sheth P N (2015). Biomass gasification models for downdraft gasifier: A state-of-the-art review. Renewable and Sustainable Energy Reviews 50: $583-593$

Reed T B \& Das A (1988). Handbook of Biomass Downdraft Gasifier Engine Systems. Solar Technical Information Program Operated for U.S. Energy Department, Colorado

Striūgas N, Zakarauskas K, Džiugys A, Navakas R \& Paulauskas R (2014). An evaluation of performance of automatically operated multi-fuel downdraft gasifier for energy production. Applied Thermal Engineering 73(1): 1151-1159

Tiangco V M, Jenkins B M \& Goss J R (1996). Optimum specific gasification rate for static bed rice hull gasifiers. Biomass and Bioenergy 11(1): 51-62
Waldheim L \& Nilsson T (2001). Heating value of gases from biomass gasification. Report prepared for: IEA Bioenergy Agreement, Task 20-Thermal Gasification Process. Report no TPS-01/16 TPS Termiska Processer AB, Studsvik, 61182 Nyköping

Yoon S J, Son Y, Kim Y K \& Lee J G (2012). Gasification and power generation characteristics of rice husk and rice husk pellet using a downdraft fixed-bed gasifier. Renewable Energy 42: 163-167

Zhang Y, Zhao Y, Gao X, Li B \& Huang J (2015). Energy and exergy analyses of syngas produced from rice husk gasification in an entrained flow reactor. Journal of Cleaner Production 95: 273-280

Zhu X \& Venderbosch R (2005). A correlation between stochiometrical ratio of fuel and its higher heating value. Fuel 84(7): 1007-1010 